30. В Москве с размахом отметили чувашский национальный праздник «Сурхури» [Электронный pecypc] // Полномочное представительство Чувашской Республики при Президенте Российской Федерации. - http://gov.cap.ru.

31. Праздник «Сурхури» в Центральной городской библиотеке им. В. Маяковского [Электронный peсурс] // Министерство культуры Российской Федерации. 25.12.2014. - http://mkrf.ru.

32. Чебоксарские дошкольники встретили старинный чувашский праздник «Сурхури» [Электронный pecypc] // НТА-Приволжье. Официальный сайт. 29.01.2016. - http://nta-nn.ru.
33. Чувашский народный праздник «Сурхури» [Электронный ресурс] // МБДОУ Центр развития ребенка - детский сад № 20 «Искринка». Официальный сайт. Новости. 21.01.2016. - http://ou7ul.a2b2.ru/news.

34. Хибатова И.А. Сценарий праздника чувашской культуры [Электронный ресурс] // http://azowsch.ucoz.ru.

35. Впервые в Московском районе столицы состоялся чувашский праздник «Сурхури» [Электронный pecypc] // Губернаторы.ru. Информационно-аналитический ресурс. 17.01.2011. - http://governors.ru.

Статья публикуется при поддержке гранта РГНФ 14-01-00360 («Праздничная культура чувашей на рубеже $X X-X X I$ вв.»).

\title{
NEW YEAR HOLIDAYS IN TRADITIONAL AND MODERN RITUALS OF THE CHUVASH
} (C) 2016

E.A. Iagafova, doctor of historical sciences, head of the Chair of Philosophy, History and Theory of World Culture Samara State University of Social Sciences and Education, Samara (Russia)

I.G. Petrov, candidate of historical sciences, leading researcher of the Department of Ethnography Institute of Ethnological Studies of R.G. Kuzeev of Ufa Scientific Center of the Russian Academy of Sciences, Ufa (Russia)

Abstract. Festive and ritual calendar of the Chuvash as agricultural and stock-raising people included rites and rituals, which ensured the success of production. Significant for the economic well-being of the Chuvash peasant was winter calendar, culminating in the New Year rites surkhuri / sēne sul / nartukan. They have typological differences in genetic ethnographic and ethno-territorial groups in the form of implementation, content and terminology making three ceremonial complexes. Cultural and dialectal features are preserved in New Year rituals in Chuvash villages till present.

Transformation of social life and family relations of the Chuvash in the XX-XXI centuries resulted in significant changes not only in the content and form of implementation, but also in understanding New Year rituals. In addition to authentic forms still observed in Chuvash villages reconstruction of ceremonies is practiced. Connection with the traditional forms is observed in ritual actions, attributes, and interpretation of the sacred meaning of the holiday.

Surkhuri as a celebration of the Chuvash regional communities (since late 2000s) has lost characteristics of a sacred action, turning into a mass ethnic show. At the same time, its role as a factor of ethnic consolidation and ethnic identity of the Chuvash in an urban multicultural environment is obvious, due to the transformation of the Chuvash society in the context of globalization.

Keywords: the Chuvash; festive and ritual culture; traditions; transformation; calendar ritualism; surkhuri; sene sul; nartukan; Christmas and New Year cycle; New Year ceremonies; ritual calendar; ethno-territorial and ethnic groups; ritual dances; divination.

УДК $394+316.7$

\section{ЭТНИЧНОСТЬ И ТРАДИЦИОНАЛИЗМ В ТВОРЧЕСТВЕ СОВРЕМЕННЫХ КАЗАХСТАНСКИХ ХУДОЖНИКОВ}

(C) 2016

А.А. Шевцова, доктор исторических наук, заведующий кафедрой международного образования и интеграции детей мигрантов в школе Московский институт открытого образования, Москва (Россия)

\footnotetext{
Аннотащия. Высокая популярность этнографических сюжетов в современном изобразительном искусстве Казахстана позволяют говорить как об этнической мобилизации в изучаемом регионе, так и о возможности исследовать этот процесс, используя произведения изобразительного искусства в качестве этнографического источника. Автор анализирует иконографию ряда произведений станковой живописи, графики, дизайна, декоративно-прикладного искусства, выделяя этнически маркированные сюжеты и характерные черты изобразительной манеры ряда авторов, соотносящихся с этнической тематикой, историей, мифологией, культурным наследием Казахстана.

Исследование путей ре(конструирования) этничности сквозь призму современной визуальной культуры привело к выделению особенностей комплексного визуального символа страны, узнаваемого даже неподготовленным зрителем. Среди них обращение к этнографическому жанру, предельно условному героическому прошлому, часто с пренебрежением к хронологии, стремление к стилизации, помещением сюжета в узнаваемый ландшафт (степь, предгорья), обилие этнических маркеров, популярный мотив дороги. Общее в изобра-
} 
зительной манере - символизм, подчеркнутая декоративность, мажорное звучание. В трансформирующемся обществе (ре)конструирование этничности может воплощаться в искусстве по-разному: от примирительного героико-патриотического визуального повествования до обращения к повседневности и трагическим страницам собственной истории.

Ключевые слова: казахи; современное изобразительное искусство Казахстана; этническая идентичность; региональная идентичность; традиционализм; современное исламское искусство; этнический ландшафт; визиотип Казахстана; казахский орнамент; декоративно-прикладное искусство; этническая мобилизация; этнический сюжет в живописи; этнический маркер в искусстве.

Постановка проблемы. Самосознание, формируемое и отражаемое искусством, - привычный объект изучения искусствоведов и культурологов [1, с. 10]. Искусство эры глобализации воспринимается как «априори наднациональное» [2], в то время как его сюжетный ряд, пафос, манера и техника исполнения, механизм экспонирования и потребления зачастую остаются традиционными [3, с. 22] и этнически / конфессионально окрашенными. Свидетельство тому - постоянные обращения к этнографическим сюжетам и этническим декоративным мотивам в современном изобразительном искусстве Центральной Азии и Казахстана, риторика «возвращения к истокам», стремление «держаться корней» и хранить «достояние предков», под которым понимается традиционная культура. Народный орнамент перекочевал на банкноты, элементы военной формы, оформление рекламных площадей и продуктов питания; орнаментированный предмет воспринимается как престижный [4, с. 12]. Сотни примеров этнографических сюжетов в современных станковой живописи, графике, дизайне Казахстана позволяют говорить как об этнической мобилизации в изучаемом регионе, так и о возможности исследовать этот процесс, используя произведения изобразительного искусства в качестве этнографического источника.

Каковы сюжетная канва и семантическое поле этнически маркированных произведений изобразительного искусства в Казахстане? Что их объединяет? Как влияет на символический ряд индивидуальная изобразительная манера и техника исполнения? Почему художники занимаются этнографическими изысканиями и берут на себя роль хранителей традиции? Можно ли говорить о существовании узнаваемого визуального образа Казахстана? В виду обширности темы данное исследование, базирующееся на изучении текстовых и визуальных архивов профилей ряда профессиональных современных казахстанских художников в социальных сетях, записях интервью и изучении художественных экспозиций [5], публикациях в СМИ, призвано лишь обозначить пути решения этих вопросов. Эстетические достоинства работ в тексте не обсуждаются.

История и методология вопроса, цель и задачи исследования. Процессы «бунтующей этничности» на постсоветском пространстве, этнической / этнорегиональной / этноконфессиональной мобилизации заслуженно породили обширную библиографию, хорошо известную читателю. Роль в формировании коллективных идентичностей классической инструментальной триады (перепись населения, карта и музей) Б. Андерсона [6, с. 178] в Европе и на постсоветском пространстве также не осталась без внимания $[7 ; 8 ; 9 ; 10]$, однако изучение одного из источников комплектования новых музейных коллекций - co- временного изобразительного искусства - в качестве этнографического источника, а не объекта искусствоведческого анализа, еще не стало мейнстримом.

Так, Э.Шторм и Э.Д. Смит акцентируют внимание на роли, которую играли в формировании национальной идентичности в живописи типичный «этнический ландшафт», героические и трагические события прошлого $[11 ; 12$, р. 11], превращающие изображаемый сюжет в «живые и неизгладимые из бытия события» в канве хронотопа - закономерной связи пространственно-временных координат» [13, с. 342, 347]. Подробный качественный анализ современного искусства народов России через призму этноконфессиональной мобилизации дан в исследованиях С.М. Червонной, в том числе вопросы инверсии религиозного и этнического самосознания $[1 ; 14]$; автором этой статьи прослежен этнорегиональный аспект творчества современных грузинских художников [15], но в отношении сравнительного этнографического изучения современного изобразительного искусства Центральной Азии и Казахстана исследовательский ресурс представляется неисчерпаемым, что подтверждает актуальность данной статьи.

Традиционный искусствоведческий анализ иконографии и техники ряда казахстанских художников $[16 ; 17 ; 18]$, демонстрирует, с одной стороны, восхищение исследователей приверженностью мастеров традиционным сюжетам, с другой - определенную усталость от них: «История и культура казахов - такого мы видим сегодня много. К ней обращаются многие, если не все...» [19]. Возможно, именно обилие и обыденность «национальных» сюжетов может объяснять недостаточное внимание к теме этноконфессиональной мобилизации в научной рефлексии.

Цель данного исследования - выявить мотивы и пути ре(конструирования) этничности посредством современного изобразительного искусства Казахстана.

Задачи исследования включают иконографический анализ сюжетной канвы, символики и изобразительной манеры ряда современных казахстанских художников в качестве этнографического источника, включая произведения живописи, графики, декоративно-прикладного искусства, определение оптимальной методологии более масштабного изучения данной темы.

Анализ данных. Сюжетика, топос, символика: «тени забытых предков». Сопоставление творчества современных казахских художников с этнографическими циклами предшественников (Н.Г. Хлудов, А.К. Кастеев, А.Г. Галимбаева), выявляет очевидную преемственность: повествовательность неспешно разворачивающегося живописного действа, жанровость, упоение цветистой орнаментикой уходящей натуры, декоративность, включение в узнаваемый окружающий ландшафт, а также «та степень изумле- 
ния и восторга, которую ощущает каждый, кто в первый раз попадает в этот необычайный край» [20]. Более того, многие современные авторы пишут условный «золотой век» своих предков кочевников до наступления ужасов принудительной коллективизации и оседлости, населяя его теми самыми, хлудовскими казахами Семиречья последней трети XIX века.

Отсюда великое множество разнообразных по качеству исполнения «перекочевок на джайляу (летние пастбища в предгорьях)», чабанов и охотниковджигитов на фоне далеких синих гор, гонцоввсадников на степных просторах с цветущими маками, дастарханов до горизонта, состязаний акынов, хоровод невест в высоких колпаках саукеле, семейных обрядов (укладывание в колыбель, разрезание пут, заплетание кос, благословение-бата и т.п.), и домашних хлопот вокруг юрты: приготовление кумыса, валяние войлока. Иногда, если художник пишет современное бытование того или иного обряда с натуры, приметы нового быта, не вписывающиеся в традиционный канон, намеренно исключаются. Даже стилизованный жанр подразумевает детальное знакомство с традиционными обрядовыми практиками, духовной и материальной культурой, что подтверждается экспликациями и интервью [21;22]. При этом художник часто напрямую объясняет смысл изображенного зрителю, сознательно беря на себя функцию хранителя традиции в век манкуртов, не помнящих родства.

Национальный костюм, в который облачены герои, может быть как вполне достоверным, скажем, для 2-й пол. XIX в., будто тщательно перерисованным из хрестоматийного альбома Айши Галимбаевой [23], так и весьма условным, превращаясь в знаксимвол. Так, традиционный белый головной платоккимешек (иносказательно, каз. - жена) маркирует «степных мадонн» Е. Толепбая.

Ряд современных мастеров с академической художественной школой отходят от реалистического фигуратива, актуализируя этничность другими приемами и сюжетами и акцентируя внимание на интуитивном поиске корней «через эпос, легенды» [16], семейные предания [21, с. 87], «надмирные» вечные ценности [17]. Этими ценностями оказывается семейное счастье, материнство, кровные узы, дети и внуки («Дедушкин сын» Е. Оспанулы, «Семья кочевника» Н. Бубэ, «Бабушка и семь внуков» Р. Юнусова). Идеальная кочевница предстает не только заботливой матерью, со спокойным достоинством хранящей очаг, но и бесстрашной луноликой амазонкой, готовой в час испытаний сражаться рядом с избранником («Воительницы» Н. Абишева).

Архетипический центр мира номада, его передвижное жилище, юрта - присутствует на каждой второй работе, иногда зримо и осязаемо, иногда - в виде шанырака, круглого навершия юрты, символизирующего не только родной очаг и наследство, но одновременно и солнечный круг, вечный круговорот жизни, и атамекен - землю предков, родину. Казахская пословица «В движении - жизнь» объясняет популярность мотива дороги, движения, пути, перекочевки. В символических композициях ему сопутствует движение вертикальное - восхождение по мировому древу («Наурыз» Н. Бубэ).
Излюбленный этнический маркер художников казахский народный орнамент с его обширным семантическим полем. 3. Мухамеджан предельно насыщает живописную плоскость своих панно благопожелательным орнаментом (бараньи рога, рога архара), петроглифами - «истоком изобразительного искусства» [16], татуировками из Пазырыкских курганов, воплощая тем самым свою «главную мысль Великую казахскую степь». Е. Оспанулы ищет собственный графический язык «между экспрессией звериного стиля скифов и статикой каменных изваяний тюрков» [21, с. 10]. Современные интерпретации традиционного орнамента востребованы и предлагаются многими исследователями и дизайнерами [24; 25]. Внимание к вещному миру позволяет художнику этнически маркировать даже натюрморт, вписав в него музыкальный инструмент (кобыз, домбру), узорчатый войлок, кожаную флягу или седло, украшение, утварь для кумыса или яблоко - символ Алматы.

«Присвоение» древнейшей истории евразийской степи, отождествление себя с населением, оставившим петроглифы, рунические надписи, сокровища сакских курганов, героические свершения и т.п. становится обыденной практикой: «Сегодняшние казахи - прямые потомки тюрков Великого Тюркского каганата» [21, с. 32]. Прошлое на кончике кисти пластично и послушно. Отсюда тяготение к пафосной героике брутальных эпических сказаний, батальным сценам, многочисленные изображения Кобланды, Бейбарса, Ертаргына, Камбара и др. Подобные произведения нередко становятся статусными подарками: «Картина с основателем казахстанского (sic!) ханства для кабинета босса подчеркнет его важность» [25], объектами престижной экономики.

Духовные поиски, отраженные в графике и живописи, позволяют говорить как об интересе к суфийскому исламу («Путь дервиша» Е. Оспанулы), так и о реликтах, порой заботливо ре(конструированных) доисламских верований, ощущении себя «живыми наследниками тенгрианства» [1, с. 9]. Акмарал Абулхаир [26] воплотила в тревожных портретах современниц хточническую природу Умай - древнейшего женского божества степи («Казахстанская готика»); шаманы-баксы с духами-помощниками появляются в произведениях 3. Мухамеджана, Н. Абишева, Е. Оспанулы, Н. Бубэ.

Особенности индивидуальной изобразительной манеры. Густонаселенная «казахская Вселенная» Нэлли Бубэ пронизана многослойной символикой: быт, заключенный в «житийные клейма», становится бытием, древние восточные города-миражи на Великом Шелковом пути вплетаются в историю современных номадов, а райское яблоко из библейского живописного цикла оборачивается алма-атинским апортом. Утонченные графические «Битвы», «Поединки» и «Всадники» Нурлана Абишева соперничают по экспрессивности с его символической живописью, в которой этника, прочувствованный рассказ о культуре и традициях своего народа важны и ценны: «Праздник кумыса», «Кюй» («Песня»), «Кызкуу» («Догони девушку»). Однако казахстанскому зрителю он больше известен как мастер алмаатинского городского пейзажа [18], сумевший запечатлеть неуловимое - прозрачный воздух и живой 
свет предгорий. Запоминающиеся графические нарративы чимкенсткого художника и этнографа Ералы Оспанулы стали подлинной энциклопедией нематериального наследия казахов. Воспевая мудрость, природный юмор, музыкальность и отвагу своего народа, доблестных героев и батыров, художник в то же время уделяет внимание мифологическим персонажам [27], «эксцентрикам степи» - caльь и сери, драматическим страницам истории («Мать», «Воспоминания моей матери»).

Яркое явление современной художественной жизни Казахстана - панно Зейнелхана Мухамеджана. Каждая его работа, выполненная в традиционной женской технике, «заложенной у казахов в генах» [16] - вышивке крючком кесте, похожа на застывшую песню-импровизацию, неслучайно его персонажи («Шаман», «Чабан», «Влюбленные») поют и музицируют. Уникальны миниатюрные скульптуры Руслана Юнусова - казахские нэцке из кости и дерева, эпические и сказочные герои (Мыркымбай, Алдар-Косе). Добродушным юмором и теплом веет от крошечных «Чайханщика», охотника-«Мергена», «Уснувшей». Миксом традиций советской поздравительной открытки и современной голливудской анимации предстают творения дизайнера Веты Нова [25]: длиннокосые девы нежно взирают на своих гламурных возлюбленных (открытки к 8 марта), казахский «Дед Мороз» (Аяз Атта) читает под елкой казахскую сказку Снегурочке. Изысканно сюрреалистичные героини Ерболата Толепбая («Мама», «Келин», «Невеста») поэтичны и узнаваемы.

При этом индивидуальные черты остаются в рамках насыщенного этническими маркерами современного визиотипа Казахстана [10, с. 10] - своего рода визуального символа страны, узнаваемого даже неподготовленным зрителем. Его характеризует обращение к этнографическому бытовому жанру (древний мудрый народ-труженик), предельно условному героическому прошлому, часто с эпическим размахом, пренебрежением хронологической привязкой или исторической достоверностью (ханы, батыры, фольклорные герои), одновременно со стремлением к стилизации, помещением сюжета в узнаваемый ландшафт - предгорья, табуны или отары в степи, обилие этнических маркеров (орнамент, костюм, юрта, кумыс, домбра), популярный мотив дороги / перекочевки. Общее в изобразительной манере - подчеркнутая праздничная декоративность (полихромность или тщательная детализация графики, увлечение орнаментикой, формальными закольцованными композициями), символизм в опоре на традиции московской и ленинградской реалистической школы, мажорное звучание - лишь усиливают эмоциональное впечатление зрителя.

В дальнейшем круг изучаемых источников может быть расширен за счет книжной иллюстрации, визуальных нарративов, карикатуры, дизайна и рекламы, декоративно-прикладного искусства, а методологию обогатить глубинными интервью и статистическим анализом.

Заключение. Исследование ряда произведений современного казахстанского изобразительного искусства в качестве этнографического источника выявило, с одной стороны, повышенный интерес мастеров к этнически окрашенным сюжетам и техникам, обусловленный в том числе, коммерческой успешностью и востребованностью подобных произведений у казахстанских и международных зрителей и критики. С другой стороны, это позволило проанализировать круг сюжетов и характерные черты изобразительной манеры ряда авторов, соотносящихся с этнической тематикой, историей, мифологией, культурным наследием Казахстана, тем, что мыслится как сокровища нации.

В трансформирующемся обществе (ре)конструирование этничности воплощается в искусстве поразному: от примирительного героико-патриотического визуального нарратива до обращения к повседневности и трагическим страницам собственной истории, от высокохудожественной живописных и графических циклов до откровенно китчевого сувенирного дизайна. Современный визиотип «золотого века» Великой Степи, апеллирующий к популярной риторике обращения к корням, пробуждения «генетической памяти» казахов, зримо отражает стремление социума заявить свои права на прошлое, настоящее и будущее в хронотопе Евразии. Осмысление и научная антропологическая и искусствоведческая рефлексия этого комплексного явления в художественной жизни Центральной Азии - дело ближайшего будущего.

\section{СПИСОК ЛИТЕРАТУРЫ:}

1. Червонная С.М. Искусство и религия: Современное исламское искусство народов России. М.: Прогресс-Традиция, 2008. 600 с.

2. Гуськов С., Новоженова А. Наш или турок // Разногласия. Музеи. Между цензурой и эффективностью. 2016. № 2 (Март). С. 35-50.

3. Ларина Е.И. Среднеазиатская этнография профессора С.П. Полякова: наука и инструментальность // Востоковедческие исследования на постсоветском пространстве. Сб. памяти проф. С.П. Полякова. М.: МГУ, 2014. С. 21-34.

4. Шевцова А.А. Казахский народный орнамент. Истоки и традиция. М.: Каз. диаспора, 2007. 240 с.

5. Полевые материалы автора: Алматы, июнь 1998 г., Зайсан, Усть-Каменогроск, июль 2005 г., Москва, сентябрь 2014 - май 2016 г.; посещение выставок, интервьюирование и изучение визуального материала художников А. Абдулхаир, Н. Абишева, Н. Бубэ, 3. Мухамеджана, Е. Оспанулы, Е. Толепбая, Р. Юнусова и др.

6. Андерсон Б. Воображаемые сообщества. Размышления об истоках и распространении национализма. Пер. с англ. В.Г. Николаева. М.: Канон-ПрессЦ, Кучково поле, 2001. 288 с.

7. ManojlovićPintarO., IgnjatovićA. (2011). National Museums in Serbia: A Story of Intertwined Identities // Building National Museums in Europe 1750-2010. Conference proceedings from European National Museums: Identity Politics, the Uses of the Past and the European Citizen, Bologna 28-30 April 2011. Peter Aronsson\& Gabriella Elgenius (eds) EuNaMus Report No 1. Published by Linköping University, 2011. P. 779-816.

8. Hajdarpašić E. Museums, Multiculturalism, and the Remaking of Postwar Sarajevo [Электронный pecypc] // (Re)Visualizing National History: Museums and National Identities in Europe in the New Millennium, ed. O.Robin. University of Toronto Press, 2008. http://jstor.org/stable/10.3138/9781442687257.8. 
9. Гринько И.А., Шевцова А.А. «Реанимируя Андерсона»: музей и карта в формировании современных идентичностей // Культурологический журнал. 2015. № 1 (19).

10. Гусейнов Г.Ч. Карта нашей родины: идеологема между словом и телом. М.: ОГИ, 2005. 214 с.

11. Storm H.J. Painting Regional Identities: Nationalism in the Arts. France, Germany and Spain, 1890-1914 // EuropeanHistoryQuarterly. 2009. P. 557-582.

12. Smith A.D. The Nation Made Real. Art and National Identity in Western Europe, 1600-1850. Oxford university press. $2013.213 \mathrm{pp}$.

13. Ухтомский А.А. Доминанта. СПб.: Питер, 2002. $448 \mathrm{c}$.

14. Червонная С.М. Все наши боги с нами и за нас. Этническая идентичность и этническая мобилизация в современном искусстве народов России. М.: ЦИМО, ИЭА РАН, 1999. 298 с.

15. Шевцова А.А. «Отражен в небесах Тбилиси»: Город и горожане в творчестве современных грузинских художников // Город в этнокультурном пространстве народов Кавказа. М.: ИЭА РАН, 2014. C. $184-200$.

16. Дуспулова Д. Зейнелхан Мухамеджан: «Я не политик, я просто художник» // Бизнес \& Власть. 2014, 03 октября. № 33 (510). С. 10-11.
17. Резникова Е. Художественный мир НэллиБубэ // Nomad-Kazakhstan. 2014. № 1/2 (53-54). C. 17-24.

18. Иванина Н.И. Мне кажется, что я Алма-Ата // Nomad-Kazakhstan. 2010. № 3. C. 29-32.

19. Иванина Н.И. Графические легенды // Транзит.kz. 2010. № 5 (25). С. 45-49.

20. Домбровский Ю.О. Хранитель древностей. Гл. IV / Собр. соч. в 6 тт. Т. 4. М.: Терpa, 1992. 398 с.

21. Ospanuly E. Four mushels. Graphics / Альбом. Текст англ.,каз., pyc. Shymkent, 2009. 296 c.

22. Каирбеков Б. Национальные традиции и обычаи. Казахский этикет. Алматы: Empire, 2012. 112 с.

23. Галимбаева А.Г. Казахский народный костюм. Альбом. А.-Ата: Казахлитиздат, 1958.80 с.

24. Омирбекова М.Ш. Энциклопедия казахского орнамента. Алматы: Алматыкітап, 2005. 240 с.

25. Коллекция, посвященная 550-летию Казахского ханства [Электронный ресурс] // Сайт дизайнера Веты Нова. - http://veta.kz/products/han.

26. Гончарова А. Кровь и гот [Электронный ресурс] // Экспресс-К: - http://express-k.kz/news/? element_id=65249.

27. Шевцова А.А. Казахская демонология глазами Ералы Оспанулы: иконография и этнография // Востоковедческие исследования на постсоветском пространстве. М.: МГУ, 2014. С. 249-254.

\section{ETHNICITY AND TRADITIONALISM IN THE CONTEMPORARY KAZAKHSTAN ART} (C) 2016

A.A. Shevtsova, doctor of historical sciences, head of the Chair of International Education and Integration of Migrant Children in School Moscow Institute of Open Education, Moscow (Russia)

Abstract. Popularity of ethnographic plots in contemporary Kazahstan's painting let us discuss ethnic mobilization in this region. Also we get possibility to analyze this process using paintings as ethnographical source. Author analyses iconography of painting, graphics, design, decorative and applied art looking for plots with ethnic makers and typical traits linked with ethnic theme, mythology and cultural heritage of Kazakhstan.

Research of reconstructing ethnicity through the contemporary visual culture shows us special aspects of complex visual symbol of the country. Among these aspects, we should line references to ethnographical genre and heroical past (often with ignoring of chronology), pursuit to stylization, using of stereotypical landscape, abundance of ethnic markers and motive of the way. Common traits of all these works are symbolism, decorativeness and major tonality.

Keywords: Kazakhs; contemporary art of Kazakhstan; ethnicity; regional identity; traditionalism; contemporary Islamic art; ethnical landscape; visual image of Kazakhstan; Kazakh ornament; decorative and applied art; ethnic mobilization; ethnic plot in painting; ethnic marker in art. 